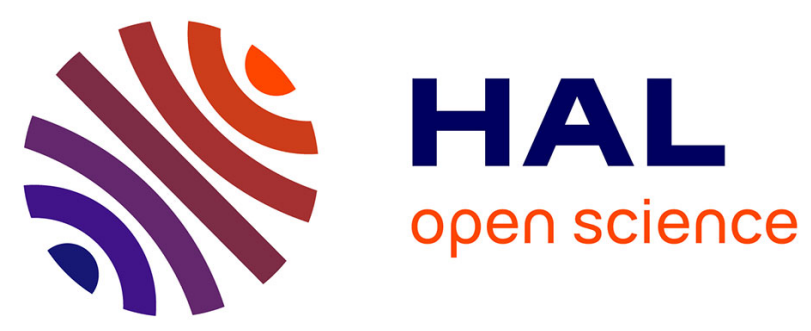

\title{
Ornamental plants architectural characteristics in relation to visual sensory attributes: a new approach on the rose bush for objective evaluation of the visual quality
}

Morgan Garbez, Ronan Symoneaux, Etienne Belin, Yves Caraglio, Yann

Chéné, Nicolas Dones, Jean-Baptiste Durand, Gilles Hunault, D. Relion, Monique Sigogne, et al.

\section{- To cite this version:}

Morgan Garbez, Ronan Symoneaux, Etienne Belin, Yves Caraglio, Yann Chéné, et al.. Ornamental plants architectural characteristics in relation to visual sensory attributes: a new approach on the rose bush for objective evaluation of the visual quality. European Journal of Horticultural Science, 2018, 83 (3), pp.187-201. 10.17660/eJHS.2018/83.3.8 . hal-01831318

\author{
HAL Id: hal-01831318 \\ https://hal.science/hal-01831318
}

Submitted on 20 Aug 2018

HAL is a multi-disciplinary open access archive for the deposit and dissemination of scientific research documents, whether they are published or not. The documents may come from teaching and research institutions in France or abroad, or from public or private research centers.
L'archive ouverte pluridisciplinaire HAL, est destinée au dépôt et à la diffusion de documents scientifiques de niveau recherche, publiés ou non, émanant des établissements d'enseignement et de recherche français ou étrangers, des laboratoires publics ou privés. 


\title{
Ornamental plants architectural characteristics in relation to visual sensory attributes: a new approach on the rose bush for objective evaluation of the visual quality
}

\author{
M. Garbez ${ }^{1,2}$, R. Symoneaux ${ }^{3}$, É. Belinn ${ }^{4}$, Y. Caraglio ${ }^{5}$, Y. Chéné ${ }^{4}$ N. Donès ${ }^{6}$, J.-B. Durand ${ }^{7,8}$, G. Hunault 9 , \\ D. Relion ${ }^{1}$, M. Sigogne ${ }^{1}$, D. Rousseau ${ }^{10}$ and G. Galopin ${ }^{1}$ \\ ${ }^{1}$ IRHS, INRA, Agrocampus Ouest, Université d’Angers, Beaucouzé, France \\ 2 Pépinières Desmartis, Bergerac, France \\ ${ }^{3}$ Unité de Recherche GRAPPE, Université Bretagne Loire, Ecole Supérieure d'Agricultures (ESA), INRA, Angers, France \\ ${ }^{4}$ Université d'Angers, Laboratoire Angevin de Recherche en Ingénierie des Systèmes (LARIS), Angers, France \\ ${ }^{5}$ AMAP, CIRAD, CNRS, INRA, IRD, UM, Montpellier, France \\ ${ }^{6}$ PIAF, INRA, UCA, Clermont-Ferrand, France \\ ${ }^{7}$ Virtual Plants, Montpellier, France \\ ${ }^{8}$ Laboratoire Jean Kuntzmann, MISTIS, INRIA Grenoble - Rhône-Alpes, Saint Ismier, France \\ ${ }^{9}$ Université d’Angers, Laboratoire Hémodynamique, Interaction, Fibrose, et Invasivité Tumorale Hépatique (HIFIH), Angers, \\ France \\ ${ }^{10}$ Université de Lyon, Centre de Recherche en Acquisition et Traitement de l'Image pour la Santé (CREATIS), Villeurbanne, \\ France
}

\section{Summary}

Within ornamental horticulture context, visual quality of plants is a critical criterion for consumers looking for immediate decorative effect products. Studying links between architecture and its phenotypic plasticity in response to growing conditions and the resulting plant visual appearance represents an interesting lever to propose a new approach for managing product quality from specialized crops. Objectives of the present study were to determine whether architectural components may be identified across different growing conditions (1) to study the architectural development of a shrub over time; and (2) to predict sensory attributes data characterizing multiple visual traits of the plants. The approach addressed in this study stands on the sensory profile method using a recurrent blooming modern rose bush (Rosa hybrida 'Radrazz') presented in rotation using video stimuli. Plants were cultivated under a shading gradient in three distinct environments (natural conditions, under 55 and $\mathbf{7 5 \%}$ shading net). Architecture and video of the plants were recorded during three stages, from 5 to 15 months after plant multiplication. Except for visual traits at the scale of the organs, panel performance was highly satisfying for most of the sensory attributes listed. Strong correlations (Spearman's coefficient ranging from 0.72 to 0.98 ) were found between them and architectural variables extracted from phytomer to plant scale data. Acceptable to very satisfying models were obtained $\left(Q^{2}\right.$ ranged from 0.49 to 0.95 , normalized RMSEP $<17.3 \%$ ) with simple ordinary least squares regression and variable transformation to encompass non-linear relationships. The proposed approach presents therefore a powerful way to gain a better insight into the architecture of shrub plants together with their visual

\section{Significance of this study}

What is already known on this subject?

- Visual quality of ornamental plants is a key parameter playing a major role in the purchase triggering for consumers. Nonetheless, it is a complex notion based on the individual and subjective appreciation.

What are the new findings?

- A new method to studying and modeling the relationships between ornamental plant architecture and main visual components. The obtained models enabled to identify architectural variables with good predictive ability and especially relevant for explaining the visual appearance of the architecture of rose bush.

What is the expected impact on horticulture?

- Within ornamental horticulture context, visual quality of plants is an important criterion for consumers looking for immediate decorative effects products. This work will make it possible to objectify the relation between the architecture of the plant and the visual perception by the consumer. It's a future tool to help innovation in ornamental horticulture.

appearance to target processes of interest in order to optimize growing conditions or select the most fitting genotypes across breeding programs, with respect to contrasted consumer preferences.

\section{Keywords}

architectural analysis, linear regression, Rosa hybrida, sensory profile, visual appearance, woody ornamental plant 


\section{Introduction}

Visual quality of ornamental plants is a key parameter playing a major role in the purchase triggering for consumers (Townsley-Brascamp and Marr, 1994; Schreiner et al., 2013; Ferrante et al., 2015). Nonetheless, it is a complex notion based on the individual and subjective appreciation of the product design or appearance by a given individual. Thus, preferences are mainly related to aesthetical judgments, although, for objective or subjective reasons, there may be differences or conflicts of judgment between people (Higginbotham, 1987; Creusen and Schoormans, 2005; Boumaza et al., 2010).

Effects of growing practices evaluated on various plant parameters measured with destructive or contactless methods are rather well-documented (Ferrante et al., 2015). Nonetheless, in such studies, a plant with pleasant visual appearance is too often seen as univocal and consumer preferences as homogeneous. Therefore even if manual or automatized grading occurs, actually the likeliness to observe a simple relation and good concordance between visual quality grades with specific preferences and expectations of the consumers, is small (Kohsel and Bennedsen, 2001; Garbez et al., 2016). From past decades, quality management of fresh horticultural products, especially fruits and vegetables, strongly benefited from the sensory evaluation science (Meilgaard et al., 2006). Its recent application on the rose bush showed also the strong relevance for providing a common background for objectifying and harmonizing visual quality studies on ornamental plants using real plants (Boumaza et al., 2009), single plant facet pictures (Boumaza et al., 2010; Huché-Thélier et al., 2011; Santagostini et al., 2014), and virtual plants presented in rotation on video (Garbez et al., 2015, 2016).

However, nowadays ornamental woody plants are still very often subjected to pruning or growth regulator applications to modulate plant growth for an empirical control of their quality. Knowledge about the variability of the architectural responses against environmental factors represents a valuable way to better control plant visual appearance with more reasoned, cheaper, and greener growing practices (Galopin et al., 2010; Huché-Thélier et al., 2011; Morel et al., 2012; Demotes-Mainard et al., 2013b; Crespel et al., 2014; Li-Marchetti et al., 2015). Understanding and controlling architecture is therefore an interesting lever to address ornamental plant design management, and more specifically to better fulfill expectations of the consumers thanks to knowledge about their requirements. Detecting links between architectural parameters and hedonic-free assessments of vi- sual traits is thus needed to investigate if putative underlying key biological processes could be targeted. This approach, necessary to address visual quality of ornamental plants, cannot remain empirical. Thus, identification of visual attributes is necessary on the one hand to analyze their relations with the architectural components, the subject of this publication, and on the other hand to further understand the preferences of the consumers. However, literature about relations between perception of plant visual appearance traits and such architectural parameters for explaining consumer preferences is still poorly documented (Scuderi et al., 2012). First studies on rose bushes demonstrated the high potential of this approach through correlative studies either using young plants, or addressing for specific aims a limited number of visual descriptors selected from a sensory method or picked out from UPOV guideline for Rosa L. (Huché-Thélier et al., 2011; Crespel et al., 2013; Santagostini et al., 2014).

The main research objectives addressed in the present study concern (1) the architectural characterization over time of the rose bush without any pruning so that all the potential basal sprouts can be taken into account, and (2) if architectural components can be identified in relation to some visual traits and used for predicting them independently of plant age and growing conditions. The same rose bush cultivar was grown under three contrasted shading conditions to induce phenotypic variability. The architecture of the plants was recorded three times over 15 months of cultivation. In parallel, visual traits of the plants were characterized through a sensory profile trial using videos presenting them in rotation as stimuli. The paper presents: (1) the sensory profile of the plants on videos using multiple sensory attributes describing general aspects of the plants and their organs; (2) the architectural monitoring over the three acquisition stages, and the generation of plant-scale architectural variables; for (3) a correlation and ordinary least square regression study with the aim to predict the relevant and consensual sensory attributes using architectural variables as predictors.

\section{Materials and methods}

\section{Plant material}

The experiment used recurrent-flowering rose bushes from the Radrazz cultivar (Rosa hybrida L. 'Radrazz', marketed under Knock Out ${ }^{\circledR}$ ) and light intensity as a means of inducing consequent phenotypic differences between plants. 'Radrazz' is a modern shrub cultivar. The flower is terminal,

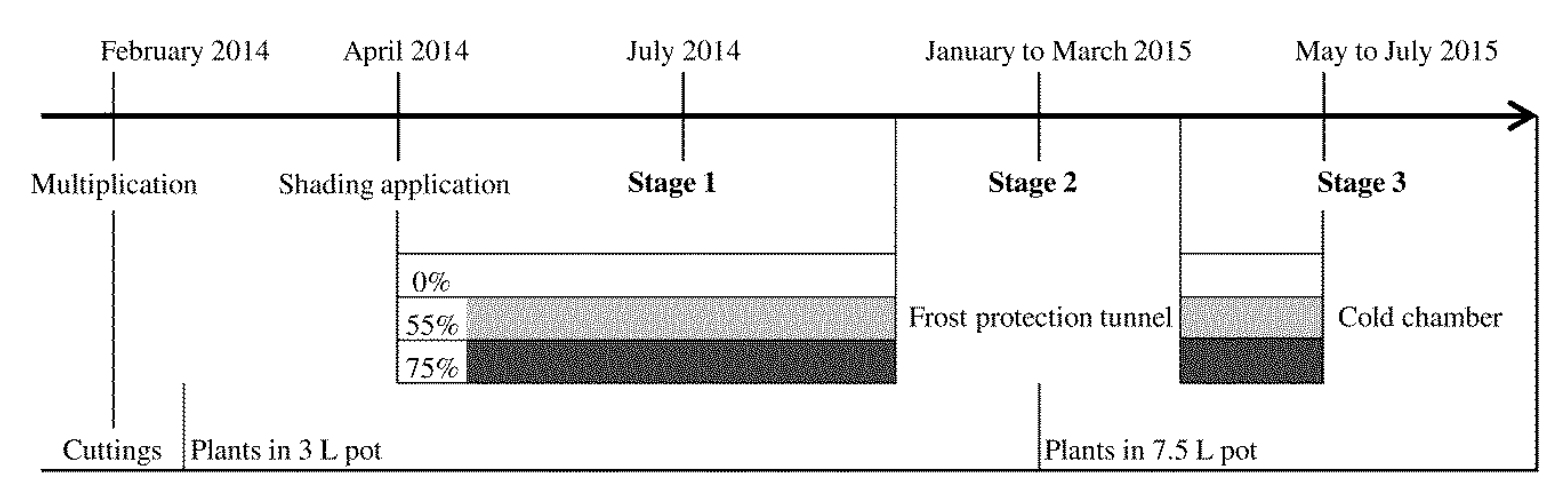

FIGURE 1. Schematic presentation of the container cultivation cultural conditions of 'Radrazz' rose bushes and stages of data acquisition periods. 
solitary and simple, red to pink Bengali flowers - red45A, with determinate growth (Morel et al., 2009). Plants were obtained from single node cuttings harvested on the $4^{\text {th }}$ February 2014 and individually placed in plugs for rooting as described in teammate protocols (Morel et al., 2012; Demotes-Mainard et al., 2013b).

\section{Growth conditions}

Plants were cultivated outdoors in pots under three shading levels in the experimental facilities of the IRHS (French Research Institute on Horticulture and Seeds, Angers, France; $47^{\circ} 28^{\prime} 45.8^{\prime \prime} \mathrm{N}, 0^{\circ} 36^{\prime} 32.3^{\prime \prime} \mathrm{W}$, altitude $48 \mathrm{~m}$ ).

As represented in Figure 1, experimental conditions started on the $25^{\text {th }}$ April 2014, with young plants in 3-L pot, aged 81 days since cutting. Harvest was chosen as time reference for dating plant age. Sixty flowering and homogeneous plants intended to be characterized were randomly and evenly assigned in three environments on a soilless culture ground: (1) without shading screen (denoted 0\%); (2) under a tunnel covered with a 55\%; or (3) 75\% shading screen. The first year the plants were placed at a density of 1.1 plant $\mathrm{m}^{-2}$. Then at mid-December 2014, plants were moved to an unheated polyethylene tunnel to prevent any frost damages on roots and future young shoots. Plants were then repotted in 7.5-L pot. Finally, plants were replaced on the $25^{\text {th }}$ February 2015 to their respective environment at a lower density (0.8 plant $\left.\mathrm{m}^{-2}\right)$.

Plants were potted in a well-draining substrate (custom mix made by Faliénor; Vivy, France) composed of Irish peat, perlite, coir (50:40:10 in volume ratio), and fertilized with 1 $\mathrm{kg} \mathrm{m}^{-3}$ of PG-Mix ${ }^{\mathrm{TM}}$ 14-16-18. Watering schedules of the three environments were individually adjusted according to rain, microclimatic conditions and substrate moisture status of the plants to guarantee no water limitation. Water was completed for fertigation with liquid 3:2:6 N- $\mathrm{P}_{2} \mathrm{O}_{5}-\mathrm{K}_{2} \mathrm{O}$ ratio solution (Plant-Prod ${ }^{\circledR} 15-10-30$; Plant Products, Leamington, ON, USA) with adjusted $\mathrm{pH}$ at 6.5 and $\mathrm{EC}$ at $1.2 \mathrm{mS} \mathrm{cm}^{-1}$.

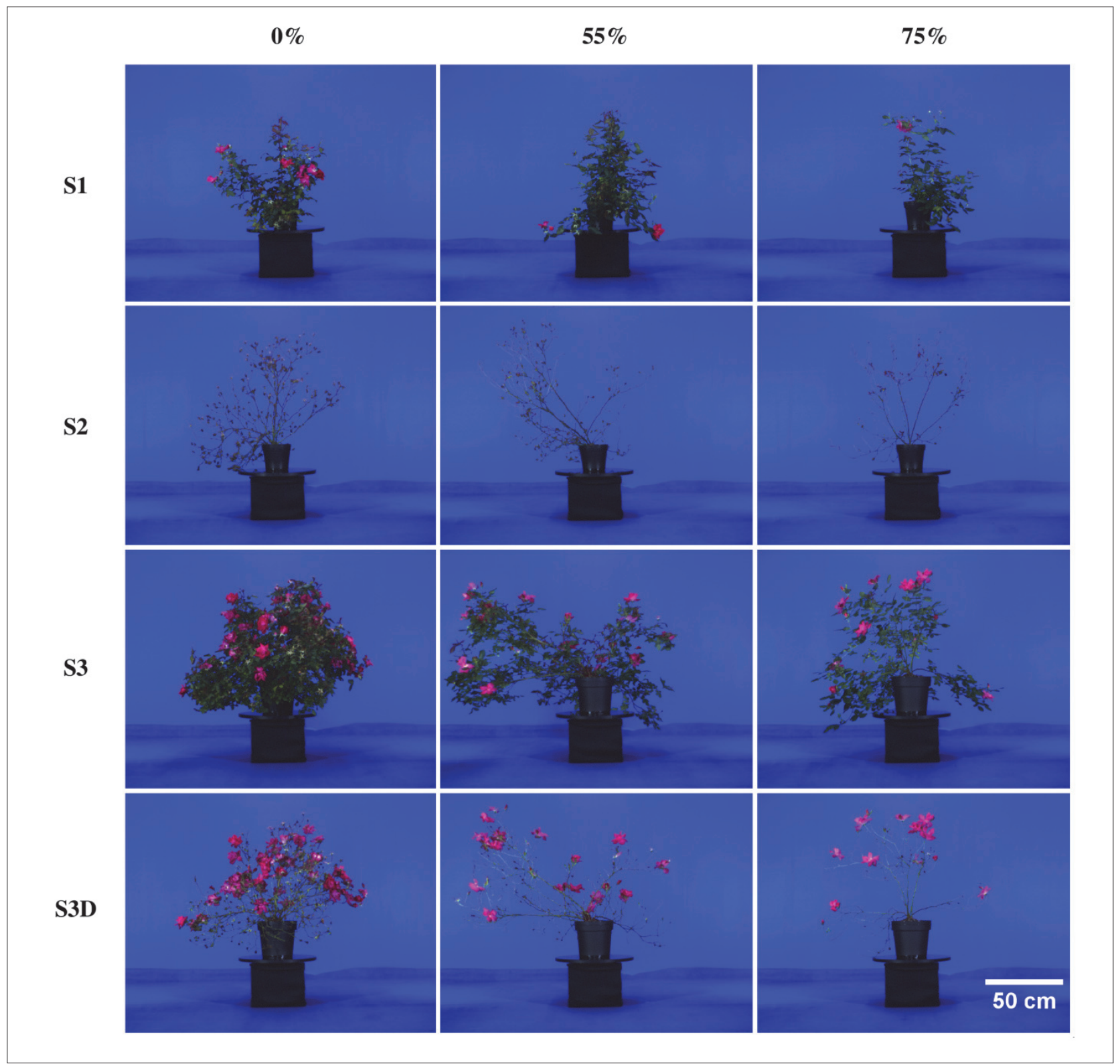

FigURE 2. Panel of cropped and reduced size images of three rose bushes from the different shading environments (from left to right: 0,55 , and $75 \%$ of shading) over the three acquisition stages (from top to bottom: S1, S2, S3), then manually defoliated at the third stage (S3D). 


\section{Plant acquisitions}

Tree times, a double characterization was realized during the 15 months: visual appearance, through a sensory profile using as stimuli rotating plant video edited from image sequences; and architecture, using a 3D magnetic digitizing contact method (Figure 1). For the three stages of development and the three shading environments, 179 rotating plant video and 132 plant architecture records were obtained for subsequent characterizations.

1. Image capture and editing of rotating plant videos. A specific enclosure was set for capturing images sequences of potted plants in rotation. It was composed of a metallic structure $(2.25 \mathrm{~m}$ height $\times 3 \mathrm{~m}$ width $\times 6 \mathrm{~m}$ length $)$ covered with an occulting black fabric to avoid uncontrolled light variations, a blue photographic cloth (DynaSun, W003; Confidence Europe $\mathrm{GmbH}$, Essen, Germany) for background, and a carpet of similar colour on the floor. Plant rotation and image capture were computationally controlled through a user-interfaced turntable (custom built device; Forumgraphic SA, Cassis, France). In order to obtain comparable images across data collection, system parameters were chosen and fixed for all the experiment duration testing the image capture on potted rose bushes of different ages from other experiments.

Center of the turntable (height of $30 \mathrm{~cm}$ ) was placed at $1.4 \mathrm{~m}$ from the background, and $4.5 \mathrm{~m}$ from a front 12 bits $10 \mathrm{Mpx}$ CMOS colour camera (GigE UI-5490SE; IDS Imaging Development Systems GmbH, Obersulm, Germany) placed at $70 \mathrm{~cm}$ height from the floor. Focus was achieved with a standard zoom lens (Tevidon ${ }^{\circledR} 2 / 10$; Docter Optics Components $\mathrm{GmbH}$, Neustadt an der Orla, Germany). Scene illumination was controlled with daylight lamps (temperature colour ranging from 5500 to $6500{ }^{\circ} \mathrm{K}$ ): four linear LED lamp lines in lateral position surrounding the turntable, two superior fluorescent tubes, and an annular LED lamp around the camera to enhance front lighting. Light variations in the scene were assessed and reduced using two-dimensional graphs of pixel intensities from the 'plot profile' function of ImageJ (Abràmoff et al., 2004) on greyscale images of the plant-less scene. Parameters for plant image sequence capture were set to: 360 images (resolution of $3840 \times 2748$ ) obtained along rotation intervals of one degree with break of seven seconds for plant stabilization before image capturing. The time to capture a complete plant image sequence was thus fixed to 42 minutes. Before each sequence acquisition, the image of the blue background with the turntable and a plant-less pot filled with substrate was recorded for image analysis purposes.

Once the image sequences for the last stage (S3) were obtained (Figure 2), all the sequences were converted in AVI videos using ImageJ (Appendix A). Video parameters chosen were $3^{\circ}$ between consecutive frames, thus 120 images per plant, with a frame rate of 10 frames s$^{-1}$ and JPEG compression.

2. Plant architecture recording. Rosa plants present stems with defined growth by terminal flowering (or abortion), and subsequent sympodial branching in all axes. For recurrent flowering varieties as 'Radrazz', axes are modules with continuous growth composed of phytomers edified by a single terminal meristem in which organogenesis ceases with autonomous floral induction (Zieslin and Mor, 1990; Le Bris et al., 1998; Morel et al., 2009; Costes et al., 2014). The phytomer is the basic structural and functional unit of vascular plant body. Generated by apical meristem of the shoots, the phytomers form the leafy axes by superposition, and higher order axes through branching resulting mostly from the outgrowth on node region of lateral bud(s) inserted at the leaf axil(s) (Barthélémy and Caraglio, 2007).

Plant architecture recording was done using the PiafDigit software (Donès et al., 2006). It consisted of encoding with a Fastrack ${ }^{\circledR}$ 3D digitizer (Polhemus, Colchester, VT, USA) the 3D coordinates of the phytomers constituting all apparent plant axes together with their topological relation (succession or branching) and some morphological features (Crespel et al., 2013; Morel et al., 2009, 2012; Li-Marchetti et al., 2015). Branching order notation followed the 'birth' organization of the axes, i.e., the first axis sprouting from the cutting was denoted as the $1^{\text {st }}$ branching order, its lateral buds growth leading to second branching order axes and so on. This primary structure was labeled in this study as the 'elementary architectural system'. Proximal axes sprouting at or under the substrate level, sometimes called 'renewal canes' (Zieslin and Mor, 1981) and empirically seen as total reiterated complexes (Costes et al., 2014; Kawamura et al., 2015)

TABLE 1. Number of samples for architectural recording, image capture and video editing for each shading environment and for the three stages.

\begin{tabular}{llcccc}
\hline $\begin{array}{l}\text { Stages } \\
\text { Shading levels }\end{array}$ & Plant age & Video & Sensory & Architecture & Relation $^{1}$ \\
\hline Stage 1 & 5 months & 59 & 57 & 53 & $52: 36 / 16$ \\
$0 \%$ & & 19 & 19 & 18 & $17: 12 / 5$ \\
$55 \%$ & 20 & 19 & 17 & $17: 12 / 5$ \\
$75 \%$ & 20 & 19 & 18 & $18: 12 / 6$ \\
\hline Stage 2 & 12 months & 60 & 57 & 46 & $45: 30 / 15$ \\
$0 \%$ & & 19 & 16 & $15: 10 / 5$ \\
$55 \%$ & 20 & 19 & 15 & $15: 10 / 5$ \\
$75 \%$ & 20 & 19 & 15 & $33: 24 / 9$ \\
\hline Stage 3 & 15 months & 20 & 57 & 33 & $11: 8 / 3$ \\
$0 \%$ & & 19 & 11 & $11: 8 / 3$ \\
$55 \%$ & 20 & 19 & 11 & $11: 8 / 3$ \\
$75 \%$ & 20 & 19 & 11 & $130: 90 / 40$ \\
\hline Total & 20 & 171 & 132 & \\
\hline
\end{tabular}

${ }^{1}$ First number indicates the number of plants characterized at both sensory and architectural levels; the second and third numbers separated by a slash detail respectively the number of observations used for calibration and for validation of the predictive models. 
of an 'elementary architectural structure stage' (Crespel et al., 2013; Li-Marchetti et al., 2015), were denoted also as first branching order axes. These axes and all their descendants were further labeled as forming the 'delayed architectural systems'. Morphological features consistently recorded throughout the experiment consisted of reporting the apex state of the axes, and measuring with a digital caliper the basal diameter of each first branching order and the midlength diameter for all the axes.

\section{Plant characterizations}

1. Visual characterization. Following an adaptation of Garbez et al. (2016) and Huché-Thélier et al. (2011), 171 different videos for the same 19 plants by shading environ- ments, at the three acquisition dates (Table 1), were selected as the products to be visually characterized by a trained panel of 20 subjects according to a sensory profile approach derived from the quantitative descriptive analysis $\left(\mathrm{QDA}^{\circledR}\right)$ method (Stone et al., 1974). During the panel formation (10 hours divided into five sessions), 17 sensory attributes were elicited for describing the plants (Table 2): 12 were related to plant general aspect traits: the volume, the height, the width of the plant; the quantities of branching, quantity of leaves, flowers, fruits, and carrier axes; the growth habit, the shape uniformity, the shape balance, and lastly the plant density. Five other attributes described organ properties within the plant: the size and the colour of the leaves, the height of the flowers within the plant, the height of the veg-

TABLE 2. Sensory attribute definitions and panel performance indices. The first block of rows reports the consensual attributes with the best panel performance; the second reports those with unsatisfying performance indices highlighted in italic characters.

\begin{tabular}{|c|c|c|c|c|c|}
\hline $\begin{array}{l}\text { Sensory } \\
\text { attribute }\end{array}$ & Definition & Repeatability $^{1}$ & Reproducibility ${ }^{2}$ & $\begin{array}{l}\text { Consonance } \\
\qquad(\%)\end{array}$ & $\begin{array}{l}\text { Discriminating } \\
\text { power } \\
\text { (F-ratio) }\end{array}$ \\
\hline Flowers $^{3}$ & $\begin{array}{l}\text { Quantity of flowers: (0) no flower to (10) very high amount of } \\
\text { flowers }\end{array}$ & $0.54 \pm 0.07$ & $0.52 \pm 0.46$ & 93.2 & $15.5^{*+*}$ \\
\hline Height & Plant height from collar: (1) very small to (10) very tall & $0.60 \pm 0.02$ & $0.84 \pm 0.15$ & 88.4 & $55.5^{+* * *}$ \\
\hline Width & Plant width along rotation: (1) very thin to (10) very wide & $0.71 \pm 0.04$ & $1.00 \pm 0.18$ & 76.9 & $8.1^{1+*}$ \\
\hline Density & $\begin{array}{l}\text { Plant density: (1) very loose, large and numerous holes within } \\
\text { the plant silhouette to (10) very dense, any holes within the } \\
\text { plant silhouette }\end{array}$ & $0.71 \pm 0.05$ & $1.45 \pm 0.32$ & 69.6 & $7.5^{* * *}$ \\
\hline Leaves $^{3}$ & $\begin{array}{l}\text { Quantity of leaves: }(0) \text { no leaf to (10) very high amount of } \\
\text { leaves }\end{array}$ & $0.76 \pm 0.05$ & $0.89 \pm 0.49$ & 79.4 & $8.1^{1+*}$ \\
\hline Volume & $\begin{array}{l}\text { Volume of the shape delimited by the plant contour: (1) very } \\
\text { small to (10) very large volume }\end{array}$ & $0.77 \pm 0.04$ & $1.03 \pm 0.21$ & 84.4 & $10.6^{*+*}$ \\
\hline Carriers & $\begin{array}{l}\text { Quantity of strong carriers axes: ( } 0 \text { ) no carrier axis to (10) very } \\
\text { numerous carrier axes }\end{array}$ & $0.79 \pm 0.07$ & $1.21 \pm 0.23$ & 72.3 & $8.1^{1+*}$ \\
\hline Fruits & Quantity of fruits: $(0)$ no fruit to $(10)$ very high amount of fruits & $0.80 \pm 0.10$ & $1.09 \pm 0.35$ & 83.4 & $12.8^{+* * *}$ \\
\hline Branching & $\begin{array}{l}\text { Quantity of branches: (0) no branch to (10) very high amount of } \\
\text { branches }\end{array}$ & $0.82 \pm 0.09$ & $1.14 \pm 0.25$ & 78.4 & $4.0^{*+*}$ \\
\hline Balance & $\begin{array}{l}\text { Balance of the plant silhouette shape: (1) very unbalanced and } \\
\text { dissymmetric to (10) very balanced plant evenly developed with } \\
\text { constant shape along the rotation }\end{array}$ & $0.93 \pm 0.13$ & $1.49 \pm 0.29$ & 65.2 & $10.6^{*+*}$ \\
\hline Habit & $\begin{array}{l}\text { Growth habit, shape elongation of the plant: (1) very spreading } \\
\text { habit to (10) very upright habit }\end{array}$ & $0.98 \pm 0.07$ & $1.09 \pm 0.21$ & 64.1 & $26.0^{+4 * *}$ \\
\hline $\begin{array}{l}\text { Flower } \\
\text { height }^{3}\end{array}$ & $\begin{array}{l}\text { Height of the flowers in the plant: (1) very down to (10) very } \\
\text { high in the plant }\end{array}$ & $0.77 \pm 0.07$ & $0.68 \pm 0.66$ & 77.9 & $43.6^{* * *}$ \\
\hline $\begin{array}{l}\text { Growth } \\
\text { height }\end{array}$ & $\begin{array}{l}\text { Height of the growth organs (axes or both axes and leaves if } \\
\text { present) in the plant: (1) very down in the plant to (10) very high } \\
\text { in the plant }\end{array}$ & $0.83 \pm 0.10$ & $0.88 \pm 0.35$ & 42.5 & $6.3^{* * *}$ \\
\hline Leaf size ${ }^{3}$ & $\begin{array}{l}\text { Average size of the leaves: (1) very small to (10) very large } \\
\text { leaves }\end{array}$ & $0.88 \pm 0.10$ & $1.02 \pm 0.52$ & 36.3 & $6.9^{+* *+}$ \\
\hline Leaf colour ${ }^{3}$ & $\begin{array}{l}\text { Green darkness of mature leaves: (1) very clear to (10) very } \\
\text { dark leaves }\end{array}$ & $0.93 \pm 0.08$ & $1.32 \pm 0.54$ & 53.3 & $3.2^{* * *}$ \\
\hline $\begin{array}{l}\text { Flower } \\
\text { clustering }\end{array}$ & $\begin{array}{l}\text { Proximity of the flowers: (1) not particularly grouped, very } \\
\text { homogeneously distributed in the plant to (10) flowers forming } \\
\text { only one distinct cluster }\end{array}$ & $1.12 \pm 0.13$ & $0.89 \pm 0.90$ & 82.4 & $39.7^{* * *}$ \\
\hline Uniformity & $\begin{array}{l}\text { Complexity of the plant shape formed by the growth organs: } \\
\text { (1) very irregular with several distinct blocks to (10) very regular } \\
\text { forming an indivisible shape }\end{array}$ & $1.17 \pm 0.12$ & $1.66 \pm 0.37$ & 60.8 & $9.0^{+* *+}$ \\
\hline
\end{tabular}

${ }^{1}$ Values are means \pm standard errors over the 8 duplicated videos of the pooled standard deviations of the subject scores between replications. ${ }^{2}$ Values are means \pm standard errors over the 171 different videos of the standard deviations of the subject scores.

${ }^{3}$ Attributes for which the score 0 means no corresponding organ in the plant, and thus for which videos of the plants during winter rest (Stage 2) were not considered for consonance and discriminating power assessments. 
etative organs (leaf and axes, or axes only) within the plant, and the clustering of the flowers. All the 171 products and four duplicates for repeatability controls, next to 31 other plant videos used for another purpose not dealt with here, were scored upon the 17 attributes on paper sheets by the 20 subjects in 8 scoring sessions of an hour in average ( 25 to 27 videos to score per subject and session). Formation and scoring sessions took place in a computer lab with identical LCD monitors in standard mode configuration with optimal preset $1920 \times 1080$ resolution, and situated to avoid communication between subjects. Subjects were not informed about cultural conditions and ages of the plants. All the videos and their duplicates were anonymized with three-digit number codes. Thus for each plant, the videos presenting respectively its three acquisition stages can also be considered as three different plants.

To limit the task difficulty for the panelists, scoring sessions consisted in the characterization of two out of three consecutive batches of videos: a first batch formed with plants presenting leaves and flowers (S1 and S3 pooled), and a second formed either with videos of plants during rest phase (S2) or with flowering plants before manual defoliation after the image acquisition for S3 and not dealt with here (Figure 2). Videos were presented using VLC media player (VideoLAN project, France) and individual playlist scripts according to an optimal design based on a William's Latin square adaptation and randomization to prevent any order effect.

Performance of the panel for each sensory attribute was assessed with common approaches presented in previous studies using rose bushes (Boumaza et al., 2010; Huché-Thélier et al., 2011; Santagostini et al., 2014; Garbez et al., 2015). Repeatability and reproducibility (Rossi, 2001) of average measurements over products were used respectively to assess the ability of the subjects to score consistently for the duplicated videos, and to score the products as the other panel subjects. The agreement between subjects was analyzed through principal component analysis (PCA),

TABLE 3. Standardized principal component analysis of weighted determined axis pooled observations $(n=33,690)$ with axisscale data extracted from plant architectures recorded during all the experiment. The first block of rows reports quantitative variables and Pearson correlations with principal components (PC) if not negligible ( $\mathrm{N}$ if $r_{P}<0.3$ in absolute value). The second block reports variables characterizing the axes and conditions treated as supplementary qualitative data with eta-squared indices measuring the proportion of variance explained on PC.

\begin{tabular}{|c|c|c|c|c|}
\hline \multirow[b]{2}{*}{ Data type - Variable } & \multirow[b]{2}{*}{ Category } & \multicolumn{3}{|c|}{ PC fulfilling Kaiser criterion and variance explained (\%) } \\
\hline & & $\begin{array}{c}\text { PC1 } \\
(37.6 \%)\end{array}$ & $\begin{array}{c}\text { PC2 } \\
(23.3 \%)\end{array}$ & $\begin{array}{c}\text { PC3 } \\
(12.8 \%)\end{array}$ \\
\hline \multicolumn{5}{|l|}{ Quantitative data } \\
\hline Length & Morphology & 0.92 & $\mathrm{~N}$ & $\mathrm{~N}$ \\
\hline Number of phytomers & Morphology & 0.88 & $\mathrm{~N}$ & $\mathrm{~N}$ \\
\hline Median diameter & Morphology & 0.78 & $\mathrm{~N}$ & $\mathrm{~N}$ \\
\hline Number of branched nodes & Morphology & 0.74 & $\mathrm{~N}$ & $\mathrm{~N}$ \\
\hline Relative location of branching insertion ${ }^{1}$ & Geometry & -0.69 & $\mathrm{~N}$ & $\mathrm{~N}$ \\
\hline Curvature $^{2}$ & Geometry & -0.65 & $\mathrm{~N}$ & $\mathrm{~N}$ \\
\hline Cord $^{2}$ angle with the vertical & Geometry & $\mathrm{N}$ & 0.62 & $\mathrm{~N}$ \\
\hline Lateral distance of the insertion ${ }^{3}$ & Geometry & -0.60 & 0.46 & 0.64 \\
\hline Lateral distance of the extremity ${ }^{3}$ & Geometry & $\mathrm{N}$ & 0.60 & 0.74 \\
\hline Vertical distance of the insertion ${ }^{3}$ & Geometry & $\mathrm{N}$ & -0.89 & 0.38 \\
\hline Vertical distance of the extremity ${ }^{3}$ & Geometry & $\mathrm{N}$ & -0.86 & 0.34 \\
\hline Azimuth ${ }^{4}$ & Geometry & - & - & - \\
\hline Basal diameter ${ }^{5}$ & Morphology & - & - & - \\
\hline \multicolumn{5}{|l|}{ Qualitative data } \\
\hline Elementary versus delayed systems & Topology & 0.01 & 0 & 0.15 \\
\hline Branching order & Topology & 0.33 & 0.02 & 0.12 \\
\hline Apex state & Morphology & 0.05 & 0.04 & 0.05 \\
\hline Stage & Condition & 0.01 & 0.01 & 0.08 \\
\hline Shading & Condition & 0 & 0.02 & 0.03 \\
\hline Stage: Shading & Condition & 0.01 & 0.04 & 0.12 \\
\hline Stage: Plant & Condition & 0.02 & 0.1 & 0.17 \\
\hline Plant & Condition & 0.01 & 0.05 & 0.09 \\
\hline
\end{tabular}

${ }^{1}$ Computed as the ratio between length of the portion from the base of the bearing axis to the insertion point of the axis in question and the total length of the bearer. It thus tends to 0 if the axis is a basal branching and to 1 if it is apical one. The ratio was set to 0 for all the branching order 1 axes.

${ }^{2}$ Computed as 1 minus the ratio between axis cord length: the axis cord is the straight line from the base to the extremity of the axis; and the axis length. It thus equal to 1 for axes completely recurved, and tends to 0 for straight axes.

${ }^{3}$ Distances are computed from the plant collar to the point mentioned in the variable name.

${ }^{4}$ Not considered in the multivariate analysis since azimuth of the axes cannot be individually compared between plants, but only extracted for plant-scale variables.

${ }^{5}$ Not considered in the multivariate analysis since it only concerned the first branching order axes, but extracted for plant-scale variables. 
with subjects as columns and products as rows, to highlight outlying subjects and compute a consonance measurement of the scores as the variance accounted for the first PC (Dijksterhuis, 1995). Finally, score differences between products were assessed by four-way mixed analysis of variance (ANOVA) modeling (Kuznetsova et al., 2015). The analysis model included the subjects as a random factor with stages and shading environments as fixed factors, plants as a nested and fixed factor within shading environments, and their interactions. Significance of the score differences between products was used to evaluate the discriminating power of the attributes and the global panel performance. This was tested through the effect on scores of the three-way interaction between plants in shading levels and stages. Discussions were undertaken for discarding attributes for which the panel performance components were eventually judged as not sufficient. Then, PCA of the 'products $x$ attributes' matrix of average scores was carried out to achieve a synthetic description of the relationships between the attributes, and of the visual characteristics of the plants presented on videos.

2. Architectural characterization for generating plant architectural descriptors. Architectural records were converted into MTG files (Multi-scale Tree Graph; Godin and Caraglio, 1998) through PiafDigit for extracting axis-scale variables using the amlPy interface module under the OpenAlea platform (Bonnard and Pradal, 2008; Pradal et al., 2008; Morel et al., 2009; Crespel et al., 2013). Variables extracted concerned the morphology, the topology and the geometry of the axes complemented with experimental information (plant index, shading level and stage of acquisition; Table 3).

Effectiveness of the architectural differences between the shading treatments over stages was assessed considering the determined axis observations, i.e., the axes which organogenesis has been stopped by floral transformation of their apex. Blind shoots were considered as determined axes too since apical meristem abortion also implies the arrest of the axis organogenesis. Branching (number of axes) and organogenesis (number of phytomers) were analyzed separately by mixed ANOVA modeling and Bonferroni's correction method for post hoc tests with error level $\alpha=0.05$. Models included stages and shading environments as fixed factors, plants as a nested random factor within the shading environments, and their interactions.

Extracted axis-scale variables were then subjected to PCA to analyze major variation sources between determined axis observations (Morel et al., 2009), and further used to generate a database of plant-scale variables that can be potentially related to the studied visual traits. Plant-scale variables selected by Crespel et al. (2013) and used in Li-Marchetti et al. (2015) were straightforwardly extracted for comparison purposes. Other variables integrating axis-scale variables at the plant level were defined with descriptive statistics such as sum, mean, median, quantiles, ranges, empirical standard deviation, minimum, maximum and coefficient of variation, according to the relevance of their use. The most important quantitative axis-scale variable highlighted by PCA was used to generate a supplementary qualitative variable determined from comparative analysis of different clustering and validation approaches. This qualitative variable was used like the branching order and the apex state to generate other more detailed variables. In parallel, the 3D coordinates of phytomers were extracted from the MTG files to be analyzed individually as 3D point clouds under the R environment (R Development Core Team, 2015). Ba- sic functions as for integration of the axis-scale variables enabled the computation of other features at whole-plant scale, such as landmark coordinates, metric distances, and spatial variances characterizing the phytomer cloud of the plants. In addition, volumetric estimation of the plants was obtained though computing the $3 \mathrm{D}$ convex hull volume enclosing the phytomers using the alphahull $R$ package (Pateiro-López and Rodriguez-Casal, 2010). Finally, the database integrated also some complementary variables built on previous ones. Thus, more than a thousand plant-scale architecture-based variables $(p=1,209)$ were collected and available as potential predictors for relationship study with the sensory attributes (categorization of the variables and examples in Table 4).

3. Relating visual and architectural characterizations. Out of the 171 products characterized by sensory profile, 130 corresponding plant architecture recordings were available (Table 1). Sensory attribute variables were defined as the average scores of the subjects by product and analyzed conjointly with plant-scale architectural descriptors. Links between pairs of sensory attribute variables and plant architectural descriptors were first evaluated with Spearman's correlation coefficient $\left(\mathrm{r}_{\mathrm{S}}\right)$ to detect eventual monotonic relationships (Huché-Thélier et al., 2011; Santagostini et al., 2014). Then, prediction of the sensory attributes variables was tested with simple linear regression through ordinary least squares (OLS), the most common and simple regression method (Næs et al., 2011; Kuhn and Johnson, 2013), using the plant architectural descriptors as potential predictors one by one without any stage- or shading-based parameters.

In order to assess their relevance and genericity, the models were first calibrated through 10 repeats of 10 -folds cross-validation on two-thirds of the data $(n=90$ plants observations over stages and shading environments), and then validated on the remaining third (Borra and Di Ciaccio, 2010; Kuhn and Johnson, 2013). Data partitioning was the same for all the sensory attributes, i.e., with a balanced-based design according to stages and shading environments with a 2:1 ratio random sampling within all the 9 crossed conditions (Table 1). Goodness of fit was evaluated with the traditional coefficient of determination and lack of fit with the root mean square error for the entire calibration data (respectively $R^{2}$ and RMSE), and through 10-10 folds cross-validation (respectively $\mathrm{R}_{\mathrm{CV}}^{2}$ and $\mathrm{RMSE}_{\mathrm{CV}}$ ). Coefficients of determination and root mean square error of prediction computed from the validation dataset (respectively $Q^{2}$ and RMSEP) were then used to assess the predictive ability of the models with unknown data. Common transformations (power, root, log, exponential and inverse) and normality supervised power-transformations of Yeo-Johnson were applied to the predictors (Yeo and Johnson, 2000) with the aim to better satisfy required linear modeling assumptions (Kuhn and Johnson, 2013) while exploiting more deeply the data still using a relatively simple modeling approach.

\section{Statistical analyses}

Statistical analyses were conducted under the R environment (R Development Core Team, 2015) with additional functions from the packages detailed thereafter. PCA were conducted with FactoMineR (Husson et al., 2016) using centered and scaled data. Variable discretization was performed with classInt (Bivand et al., 2015), by increasing number of classes through k-means (Steinley, 2006) and Fisher-Jenks algorithms (Murray and Shyy, 2000; Anchang et al., 2016). Quality and stability of the solutions were assessed using elbow graphical method, clusterwise Jaccard similarity sta- 
tistics under bootstrap resampling with $f p c$ (Hennig, 2008, 2015), and Davies-Bouldin cluster separation measurements (Davies and Bouldin, 1979) with clusterSim (Walesiak and Dudek, 2015). Mixed models were designed using Ime4 (Bates et al., 2016) and analyzed with ANOVA function of car (Fox et al., 2016) with type II sums of squares procedure (Langsrud, 2003). Subsequent multiple comparisons were done according to the Bonferroni's adjustment method on least-squares means from lsmeans (Lenth, 2016). When required, Kenward-Roger's degrees of freedom estimations were used for statistical inferences (Spilke et al., 2005; Kuznetsova et al., 2015). Data partitioning and modeling between sensory and architectural data were done using caret (Kuhn, 2016).

\section{Results}

\section{Visual characterization}

All the attributes were significantly discriminant (the product effect, i.e. the interaction 'plant : shading : stage', was highly significant with $p$-value $<0.001$ ) indicating thus a relatively acceptable global panel performance (Table 2). Means and standard errors of repeatability measurements for all the attributes except 'uniformity' and 'flower clustering' were relatively low and not so variable (maximum $M=$ 1.17 and maximum $S E=0.13$ ), indicating very little and similar differences of the subject scores over duplicated videos. Reproducibility measurements indicated that differences between subject scores on same videos were also rather low

TABLE 4. Examples of architectural variables at plant-scale gathered according to methods used and description categories proposed from the 1209 variables extracted.

\begin{tabular}{|c|c|c|c|c|}
\hline Method/Category & \multicolumn{4}{|c|}{ Examples of variables } \\
\hline \multicolumn{5}{|c|}{ Direct integration of the axis-scale variables } \\
\hline \multirow[t]{7}{*}{ Morphology } & \\
\hline & \multirow{2}{*}{\multicolumn{4}{|c|}{$\begin{array}{l}\text { Number of open flowers, Number of dry fruits, Number of open and faded flowers } \\
\text { Proportion of flowering axes, Proportion of vegetative axes }\end{array}$}} \\
\hline & & & & \\
\hline & \multicolumn{4}{|c|}{ Cumulated number of phytomers of the determined axes } \\
\hline & \multicolumn{4}{|c|}{ Cumulated length of the vegetative axes } \\
\hline & \multirow{2}{*}{\multicolumn{4}{|c|}{$\begin{array}{l}\text { Mean number of branched nodes, Mean length, Mean diameter at median length } \\
\text { Mean length of the axes ended by a fresh to dry fruit }\end{array}$}} \\
\hline & & & & \\
\hline \multirow[t]{4}{*}{ Topology } & \multicolumn{4}{|c|}{ Number of $1^{\text {st }}$ branching order axes } \\
\hline & \multicolumn{4}{|c|}{ Maximum branching order } \\
\hline & \multicolumn{4}{|c|}{ Mean branching order } \\
\hline & \multicolumn{4}{|c|}{ Mean relative location of branching insertion for the $2^{\text {nd }}$ branching order axes } \\
\hline \multirow[t]{5}{*}{ Geometry } & \multicolumn{4}{|c|}{ Mean cord angle, Mean lateral distance } \\
\hline & \multicolumn{4}{|c|}{ Median lateral distance } \\
\hline & \multicolumn{4}{|c|}{ Quantile $5 \%$ of the cord angle } \\
\hline & \multicolumn{4}{|c|}{ Coefficient of variation of the lateral distance } \\
\hline & \multicolumn{4}{|c|}{ Standard deviation of vertical distance } \\
\hline \multicolumn{5}{|c|}{ Axis length clustering } \\
\hline & \multicolumn{4}{|c|}{ Number of axes per identified length class ${ }^{1}$, summary statistics detailed thereafter } \\
\hline & Class label & Intervals (cm) & $M \pm S E(\mathrm{~cm})$ & $n$ determined axis observations \\
\hline & - tiny & {$[0 ; 7]$} & $2.4 \pm 0.0$ & 20.551 \\
\hline & - small & {$[7 ; 18]$} & $11.9 \pm 0.0$ & 8.011 \\
\hline & - medium & {$[18 ; 35]$} & $23.8 \pm 0.1$ & 4.202 \\
\hline & - long & {$[35 ; 88]$} & $46.1 \pm 0.3$ & 926 \\
\hline \multicolumn{5}{|c|}{ Phytomer cloud 3D analysis } \\
\hline & \multicolumn{4}{|c|}{ Convex hull volume } \\
\hline & \multicolumn{4}{|c|}{ Maximum width, maximum height } \\
\hline & \multicolumn{4}{|c|}{ Height of the barycenter, Median height, Quantile $95 \%$ of pairwise lateral distances } \\
\hline & \multicolumn{4}{|c|}{ Cumulated variances on the 3 dimensions, cumulated variances on the horizontal plane } \\
\hline Mixing variables & different $\mathrm{m}$ & & & \\
\hline & Mean numb & f phytomers on ti & rmined axes & \\
\hline & Number of $a$ & divided by maxi & anching order & \\
\hline & Cumulated & diameter of $1^{\text {st }}$ & ng order axes & \\
\hline & Number of $\mathrm{I}$ & axes divided by & & \\
\hline & Mean relativ & cation of branchi & rtion of the $2^{\text {nd }}$ & ing order long axes \\
\hline & Cumulated & th of the short ax & led by volume & \\
\hline & Standard de & ion of the lateral & e of the mediun & \\
\hline & Mean curva & of the $1^{\text {st }}$ and $2^{\text {no }}$ & ing order long & \\
\hline & Interquartile & ge of the azimuth & long and medic & \\
\hline & Range of th & rd angle of the $\mathrm{m}$ & axes & \\
\hline & Maximum w & divided by maxir & ight & \\
\hline
\end{tabular}

${ }^{1}$ Fisher-Jenks and k-means algorithms assessed for addressing the axis length clustering led to the same results. 
and stable except for 'uniformity', 'flower clustering', 'flower height', 'leaf colour', and 'leaf size' ( $M$ over 1.50; $S E$ over 0.50 ), indicating more relative differences between subject scores on same videos, eventually coupled with difference inconsistencies between the videos and the subjects. Finally, acceptable to very high consonance measurements confirmed with previous results the very good performance and consensual appropriation of the 11 other attributes out the 17 (Table 2).

Principal component analysis (PCA) of the average score matrix for the 171 products and the 11 selected sensory attributes allowed to identify some relations between visual characteristics, and to highlight how they structured the plants throughout shading environments and vegetation stages (Figure 3). Four principal components (PC) were considered according to the Kaiser criterion, which explained 93.4\% of the overall variance. However the first plan accounted for $70.9 \%$ and was sufficient to well discriminate main characteristics of the plants within stages and shading environments. Globally, PC1 and PC2 structured the plants according to V-shaped patterns separating the plants characteristics chronologically, and then with large to more subtle differences between shading levels. PC1 (45.8\% of the variance) synthesized plant dimensions, branching and shape equilibrium over stages, with the shading level diminution. Not surprisingly, it reflected very high to moderate correlations between 'branching' and 'carriers', 'volume', 'width', and 'height', and then 'balance'. Highest Pearson correlations for 'balance' were with carriers $\left(r_{\mathrm{P}}=0.62\right)$ and branching $\left(r_{\mathrm{P}}=\right.$ $0.60)$ which presented the strongest association $\left(r_{\mathrm{P}}=0.92\right)$ between all attributes pairs. Plant characteristics were essentially structured by age and sub-structured by shading level diminution. Interestingly, scores for plants grown under $75 \%$ of shade were systematically lower than those grown under 0 and 55\% which were more similar. PC2 (25.1\%) strongly reflected the expected very high correlation between 'leaves' and 'flowers', and their respective high and moderate correlation with plant density. PC2 opposed those attributes to 'fruits' and 'habit' presenting a negligible correlation $\left(r_{\mathrm{P}}=\right.$ 0.25 ), and 'height' also moderately reflected on PC2, with the

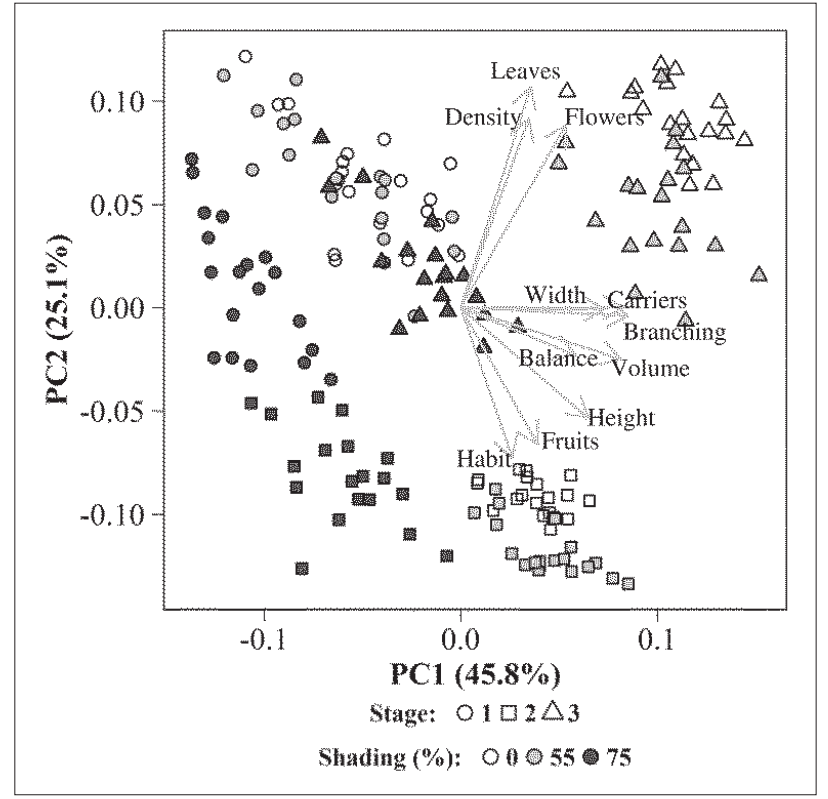

FIGURE 3. Biplot of the standardized principal component (PC) analysis of the mean 'product $\times$ attributes' matrix. The 171 plant videos being the products (rows) are plotted using grayscale shades for shading environments, and symbols for acquisition stages. The arrows indicate the direction of the 11 sensory attributes (the columns, defined as average subject scores by product).

strongest correlation observed between 'fruits' and 'leaves' but with a low opposition link $\left(r_{\mathrm{P}}=-0.42\right)$. It thus showed a structuration of the products according to the presence or absence of leaves and flowers, separating, as expected, S1 and S3 far from S2 plant characteristics. Then, it showed also a sub-structuration within stage groups according to the quantity of leaves and flowers for S1 and S3; and according to density, habit, fruits and height for the three stages enabling

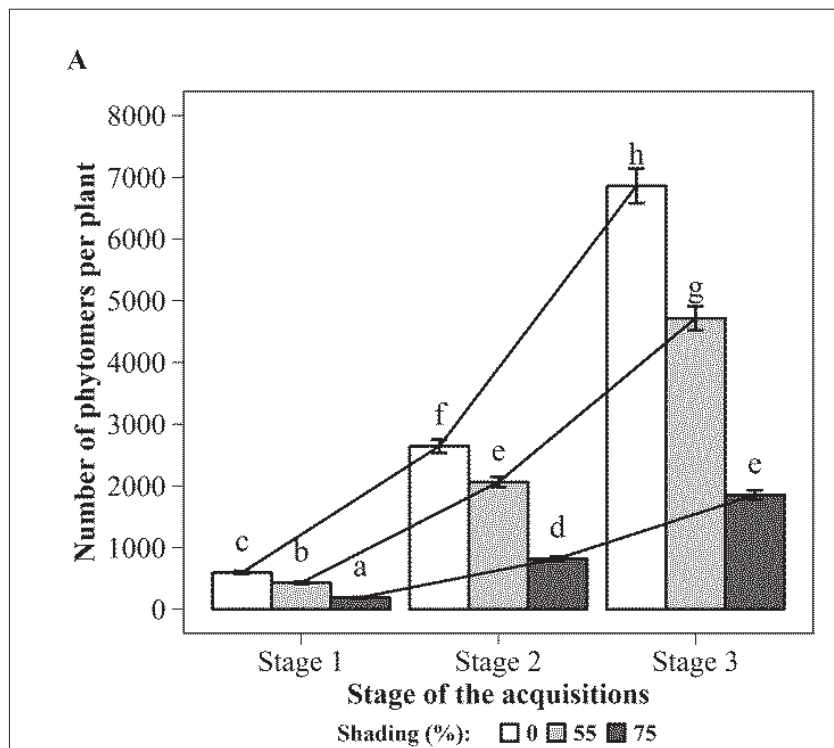

B

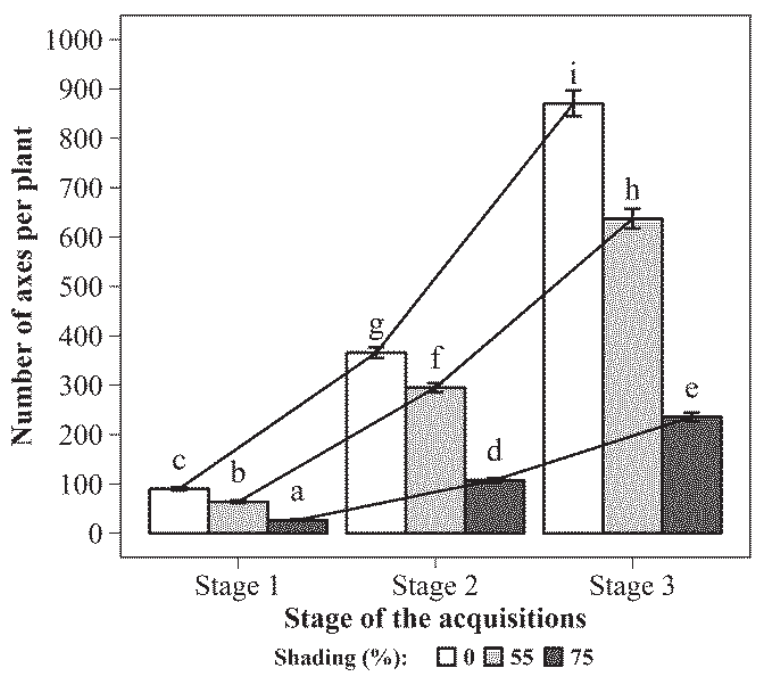

FigURE 4. Whole-plant organogenesis (A) and branching (B) considering determined axis observations across shading levels and over stages. Values are least-squares mean estimates with standard errors obtained from generalized linear mixed models with Poisson distribution of measurements made on $n=11$ to 18 plants, for a total of $N=132$ plant architecture records. Different letters indicate significant differences detected with the Bonferroni's post hoc test (error level $\alpha=0.05$ ). 
to separate the three shading levels for their characteristics at S2 and S3. However, it only separated plants grown under the highest shading level at S1.

Thus, the subjects were able to detect various noticeable visual differences easily explainable by shading and plant age. However the large to moderate inertia observed (Figure 3) within the shading environments at each stage indicated that various within-crop visual differences between plants were perceptible. Thus subsequent relations between architecture and visual appearance were addressed considering the videos with their corresponding recorded plant architecture, as different plant observations for taking in account all the observed variability.

\section{Architectural characterization}

Throughout the three stages, 41,341 axis observations were collected; some axes being eventually observed up to three times; $81.5 \%$ of the observations concerned determined axes with $21.7 \%$ of them being blind shoot observations, $18.3 \%$ were for vegetative axes and $0.2 \%$ were unclassified. In average, number of determined axes and their number of phytomers per plant presented similarly a decrease according to shading intensity, with respective increase over stages, while respective variations increased with plant development (Figure 4). Poisson distributions with log-link function, often more adapted for count data modeling, enabled to circumvent assumption violations observed with linear modeling. Models fitted well the data at hand (over dispersion Chi-square tests both presented $p<0.001$ ), and both were highly relevant and presented low effects from plants as suggested by conditional and marginal $R^{2}$, both over 0.97 for the two models (Nakagawa and Schielzeth, 2013). For both the two variables, deviance table analyses confirmed the significant effects from stage and shading, as their interaction (Wald Chi-square test $p$-values <0.001), and $95 \%$ confidence interval of the variance accounted by the plants within shading environments revealed that, event low, the effects from plants were significant. Results reflected the influence of the light intensity for plant development through both organogenesis and branching processes of the primary growth.

Clustering approaches used for the analysis of the length of the axes, chosen for its larger variance and constancy of the metric unit (contrarily to phytomer length), suggested that, when considering the experimental conditions separately (data not shown) or pooled, an optimal and consistent solution was obtained with 4 classes. Identified classes, latter respectively called: tiny, short, medium, and long axes which characteristics for the determined axis observations are presented within Table 4, were observed in all the plants whatever the stage and the shading level. Interestingly relative distribution of the classes according to branching orders and the two types of architectural systems used (elementary versus delayed) highlighted a recurrent and rather stable pattern in the three shading environments and over stages. Notably, the first axis of the cuttings was medium, carrying long, medium, short and tiny axes, while the first branching orders of the delayed architectural systems in almost all the observations were long axes.

Then, before generating the plant-scale architectural variables used thereafter, length classes were attributed to the vegetative axes for consistency in the database, and since they were present on the plants characterized by the panel.

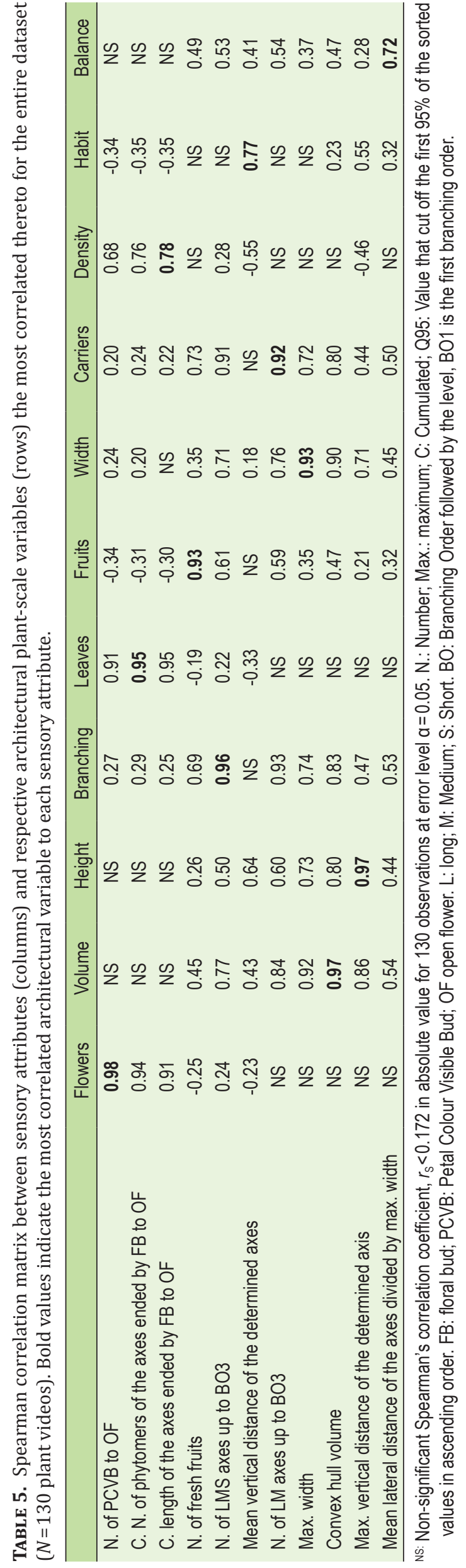


TABLE 6. Predictive abilities of the OLS models minimizing the root error mean square error on validation test set (RMSEP) to predict each sensory attribute.

\begin{tabular}{|c|c|c|c|c|c|c|}
\hline \multirow[t]{2}{*}{ Attribute } & \multirow[t]{2}{*}{ Architectural variable } & \multirow[t]{2}{*}{ PP } & \multicolumn{2}{|c|}{$\begin{array}{l}\text { Model calibration }{ }^{1} \\
n=90 \text { plant videos }\end{array}$} & \multicolumn{2}{|c|}{$\begin{array}{l}\text { Model validation } \\
n=40 \text { plant videos }\end{array}$} \\
\hline & & & $R_{\mathrm{CV}}^{2}$ & $\operatorname{RMSE}_{\mathrm{CV}}$ & $Q^{2}$ & RMSEP \\
\hline Flowers & N. of OF & SR & $0.97 \pm 0.03$ & $0.49 \pm 0.19$ & 0.95 & 0.53 \\
\hline Volume & Convex hull volume & CR & $0.95 \pm 0.02$ & $0.40 \pm 0.09$ & 0.95 & 0.39 \\
\hline Height & Max. vertical dist. of the determined axes & YJ & $0.95 \pm 0.03$ & $0.44 \pm 0.09$ & 0.93 & 0.46 \\
\hline Fruits & N. of fresh fruits & $\mathrm{SR}$ & $0.95 \pm 0.04$ & $0.47 \pm 0.13$ & 0.91 & 0.63 \\
\hline Branching & N. of LMS axes up to BO4 & SR & $0.93 \pm 0.04$ & $0.53 \pm 0.12$ & 0.94 & 0.47 \\
\hline Leaves & C. length of the axes ended by FB to OF & SR & $0.92 \pm 0.05$ & $0.81 \pm 0.24$ & 0.96 & 0.49 \\
\hline Carriers & N. of $L M$ axes up to the $\mathrm{BO} 3$ & Raw & $0.83 \pm 0.08$ & $0.66 \pm 0.14$ & 0.89 & 0.49 \\
\hline Width & Max. width (of the phytomer cloud) & YJ & $0.88 \pm 0.08$ & $0.50 \pm 0.12$ & 0.84 & 0.55 \\
\hline Habit & Q95 vertical dist. divided by Q95 lateral dist. & CR & $0.63 \pm 0.23$ & $0.81 \pm 0.18$ & 0.66 & 0.80 \\
\hline Density & N. of FB to OF & SR & $0.61 \pm 0.20$ & $1.11 \pm 0.17$ & 0.67 & 0.97 \\
\hline Balance & Max. width divided by mean vertical distance & C & $0.54 \pm 0.19$ & $1.13 \pm 0.22$ & 0.49 & 1.09 \\
\hline
\end{tabular}

${ }_{1}$ Values are means \pm standard deviations computed from 10 repeats of 10 -fold cross-validation (CV). PP: Pre-processing transformation of the architectural variables, YJ: Yeo-Johnson; SR: Square Root, CR: Cubic Root; C: Cube. N: Number; Max.: maximum; C: Cumulated; Q95: Value that cut off the first $95 \%$ of the sorted values in ascending order. FB: Floral Bud; OF: Open Flower. L: Long; M: Medium; S: Short. BO: Branching Order followed by the level, B01: first branching order.

\section{Relating visual and architectural characterizations}

Significant high to very high correlations were found for all the sensory attributes with at least one architectural plantscale variable (Table 5). Very strong relations were found for the attributes assessing quantity and metric traits, the smallest Spearman's correlation coefficient $\left(r_{\mathrm{s}}\right)$ was 0.92 between 'carriers' and the number of long and medium axes up to the third branching order; and the highest was 0.98 between 'flowers' and the number of floral buds with petal colour visible and open flowers. Lower but still high correlations, ranging from 0.72 to 0.78 , were found for 'balance', 'density', and 'habit'. While correlations of the architectural variables the most related to 'habit' and 'balance' with the other attributes were indeed lower, the cumulated length of the axes ended by a floral bud to an open flower was much more correlated to 'flowers' and 'leaves' than with 'density'. Overall, similar correlations were found for the same attributes with different variables and on the opposite, especially with the variables related to 'flowers', 'leaves', and 'density'; to 'carriers' and 'branching'; then to 'volume', 'width', and 'height'.

Correlations do not imply causations and may vary considering the sub-samples studied. Thereby, cross-validation on calibration data and validation on unknown data undertaken using OLS models with predictor transformations enabled the predictive efficiency of the available plant-scale architectural variables to be assessed more robustly. Table 6 summarizing the statistics of the models minimizing the prediction error with unknown data (RMSEP) showed that the most correlated architectural variables highlighted previously were not necessarily those leading to the best models, and that non-linear relationships were in most cases much more adapted. Overall, predictive abilities of the models obtained were quite remarkable especially for the sensory attributes related to metric and quantity traits. The less accurate model presented a relative error of prediction that did not exceed $17.3 \%$, corresponding to the range normalized RMSEP of 1.09 for the attribute 'balance'. Models with lesser performances in prediction were obtained for 'density', 'habit', and 'balance', suggesting potential links between panel performance for the sensory attributes and predictive abilities of the models that can be expected.

\section{Discussion}

Light modulation through shading enabled to induce phenotypic plasticity for the architecture of the 'Radrazz' rose bush. As already highlighted and especially exploited for the production of cut roses, results confirm the strong influence of light on the rose architecture, especially for its initial signal role in the regulation and expression of the process related to organogenesis and branching. (Zieslin and Mor, 1990; Crespel et al., 2014; Leduc et al., 2014).

From ecological and botanical points of view, results strengthen observations made about the large phenotypic plasticity of shrubs, often in response to light gradients, enabling them to adopt highly contrasted architectural development strategies according to local conditions (Valladares et al., 2000; Kawamura and Takeda, 2002, 2004; Pearcy et al., 2005; Charles-Dominique et al., 2010, 2012, 2015; Charles-Dominique, 2012; Sterck et al., 2013; Guzmán and Cordero, 2016).

This study allows to analyze the architecture of the 'Radrazz' rose bush and more broadly to provide information on the architectural development of shrubs throughout their life cycle. To resume the observed variability between axes and for predicting branching and carrying branch amounts, present results highlighted the relevance of the axis length based segmentation proposed, e.g., as used for apple tree architecture phenotyping and modeling (Costes et al., 2003; Pallas et al., 2016). Indeed, with age, delayed branching (proleptic), which is discernible by little scaly phytomers at the basis of the axes, is more and more prevalent within plants. The contrasted plants obtained with the shading experiment design, complementary results showed that this axis-lengthbased segmentation provided a quite stable pattern for the axis length distribution closely linked to branching orders within plants. Most of the basal sprouts leading to the architectural systems here labeled as 'delayed' were carried by longer axes, well supporting the first part of the definition for reiteration summarized in Costes et al. (2014): a shoot with a comparable or longer length than its parent shoot and that partially or totally repeats the parental branching system. However, together with length, the orientation of the first branching order axes suggest quite different functions 
and different profiles between shading conditions. Supporting the reiteration definition with respect to the architectural unit and its total reiteration concepts (Barthélémy and Caraglio, 2007), quite relevant for tree life cycle (Raimbault and Tanguy, 1993; Fay, 2002; Ishii et al., 2007), seems thus to present some inconsistencies for transposing the pattern and terminology used for trees to the rose bush and more generally to shrubs (Barthélémy and Caraglio, 2007; Y. Caraglio and G. Galopin, pers. commun.). Indeed, to observe plainly the Champagnat model (Hallé et al., 1978; Costes et al., 2014), 'Radrazz' has to develop relay and renewal shoots, seen up to now as reiterated complexes, but quite different from the 'elementary architectural structure stage' (Crespel et al., 2013; Li-Marchetti et al., 2015) and its development. Nonetheless, by definition, total reiteration does not lead to newest axis categories and thus should not be integrated to define neither the architectural model, nor the architectural unit. Similar observations led to revisit the Tomlinson model for basitonic branching plants (Cremers and Edelin, 1995). We may ask if the reiteration process for shrub plants should be revisited or refined to integrate the hypothesis that this process may be necessary to the architectural unit construction ('establishement phase', see Barthélémy and Caraglio, 2007) rather than a duplication of the first primary axis. Future analysis of the data using Hidden Markov chains Tree (HMT) model (Durand et al., 2005) together with similarity and distance indices between tree-structured data (Ferraro and Godin, 2000, 2003; Segura et al., 2008) to investigate finely the typology of the axes together with their topology and mutual matching may enable addressing more deeply such a hypothesis to further propose more relevant concepts for the life cycle pattern of shrubs forming bushes.

The study demonstrated the relevance of the method proposed for studying the relationships between plant architecture and main visual components. Video stands enabled the avoidance of all possible product alteration during sensory tasks, especially critical for the state of the flowers. During panel formation, 17 sensory attributes were finally proposed. They were not all strictly similar but very close and coherent with the vocabulary and attributes highlighted for virtual 'Radrazz' rose bushes assessed using video (Garbez et al., 2015, 2016), or for real ones assessed directly or using unique plant facet photographs (Boumaza et al., 2009, 2010; Huché-Thélier et al., 2011; Santagostini et al., 2014). Among the 17 sensory attributes, the panel performance was good enough for 11 of them. Consensual attributes were related to plant size, plant shape, and quantification of the organs. The six other attributes not considered here are not uninteresting so far. They may be more suitable and relevant for studying other cultivars than 'Radrazz', or for experiments with other cultural practices. Besides, enhancing panel training with more precise protocol notation, definitions, and product references for the attributes and practice scaling test tasks with feedback for calibration is highly recommended (Rainey, 1986; Wolters and Allchurch, 1994; Labbe et al., 2004; Findlay et al., 2007). Furthermore, multiple methods to present the stimuli may be investigated. For example, presenting organs ex-planta on static images as stimuli for assessing characteristics at the organ scale such as 'leaf size', or also 'flower colour intensity' or 'flower size' not investigated here, may be thus more efficient for the characterizations at the organs scale.

Finally, results obtained previously using virtual rose bush videos were confirmed with real plant material, with the validation of a protocol (number of videos, scoring ses- sions, and number of subjects). The obtained models enabled us to identify architectural variables with good predictive ability and especially relevant for explaining the visual appearance of the architecture of the rose bush. They reflected branching, growth and sexual expression of the axes as their structure in space, especially critical in the architectural establishment of the rose bush. Such variables enabled here the characterization of the plants cultivated under three contrasted shading environments with a reduced and coherent set of features over time. The large number of architectural variables that can be obtained, as here considering the methodological choice made, led to numerous comparable predictive models with quite acceptable results for each sensory attribute. Such results should thus lead researchers to carefully address the relevance of the variables selected from biological and practical viewpoints, and thus investigate more specific analyses, merging expert knowledge and advanced statistical methods adapted to variable selection and modeling under the ' $n<p$ ' conditions (Zucchini, 2000; Kuhn and Johnson, 2013; Silva et al., 2013) as illustrated previously with virtual rose bush and predictive image analysis-based models (Garbez et al., 2016). Upcoming analyses will address on the real plants the relevance of this previously tested image analysis method with more elaborated predictive modeling procedures, which may present relevant results, especially for sensory attributes concerning complex multidimensional visual traits, as here with the plant growth habit, its density and its balance. Improvements in the approach may concern image (size and resolution) and scene management for video editing in order to provide the most fitting plant visualization. Comparing results obtained from same plants presented using different stands is nevertheless necessary to gain more precise insights in the visual perception of ornamental plants.

\section{Acknowledgments}

The authors thank the Pays de la Loire Regional Council for their financial support; as the Pépinières Desmartis nursery and the National Association for Research and Technology (ANRT) for the Industrial Agreements for Research Training grant awarded (CIFRE grant number 2013/0410). The authors thank also Liu-Ji Harada for his investment during the data collection along his internship; all the people who took part in the sensory experiments; as Rémi Gardet and his team (INEM) from the Agrocampus Ouest Experimental Station for the crop monitoring support.

\section{References}

Abràmoff, M.D., Magalhães, P.J., and Ram, S.J. (2004). Image processing with ImageJ. Biophotonics Int. 11, 36-42.

Anchang, J.Y., Ananga, E.O., and Pu, R. (2016). An efficient unsupervised index based approach for mapping urban vegetation from IKONOS imagery. Int. J. Appl. Earth Observ. and Geoinform. 50, 211-220. https://doi.org/10.1016/j.jag.2016.04.001.

Barthélémy, D., and Caraglio, Y. (2007). Plant architecture: a dynamic, multilevel and comprehensive approach to plant form, structure and ontogeny. Annals of Botany 99, 375-407. https://doi.org/10.1093/ $\mathrm{aob} / \mathrm{mcl} 260$.

Bates, D., Maechler, M., Bolker, B., and Walker, S. (2016). lme4: Linear mixed-effects models using 'Eigen' and S4. https://cran.r-project. org/package $=\operatorname{lme} 4$.

Bivand, R., Ono, H., Dunlap, R., and Stigler, M. (2015). classInt: Choose Univariate Class Intervals (Version 0.1-23). https://cran.r-project. org/package= classInt. 
Bonnard, C., and Pradal, C. (2008). amlPy Reference Manual. http://openalea.gforge.inria.fr/wiki/lib/exe/fetch.php?media= documentation:amlpy_manual.pdf.

Borra, S., and Di Ciaccio, A. (2010). Measuring the prediction error. A comparison of cross-validation, bootstrap and covariance penalty methods. Comput. Stat. \& Data Anal. 54, 2976-2989. https://doi. org/10.1016/j.csda.2010.03.004

Boumaza, R., Demotes-Mainard, S., Huché-Thélier, L., and Guérin, V. (2009). Visual characterization of the esthetic quality of the rosebush. J. Sensory Studies 24, 774-796. https://doi.org/10.1111/ j.1745-459X.2009.00238.x.

Boumaza, R., Huché-Thélier, L., Demotes-Mainard, S., Le Coz, E., Leduc, N., Pelleschi-Travier, S., Qannari, E.M., and Guérin, V. (2010). Sensory profiles and preference analysis in ornamental horticulture: The case of the rosebush. Food Qual. and Pref. 21, 987-997. https:// doi.org/10.1016/j.foodqual.2010.05.003

Charles-Dominique, T. (2012). Analyse des relations entre plasticité architecturale des buissons et prolifération de leurs populations. $\mathrm{Ph} . D$. Thesis (Université de Montréal - Université Montpellier II).

Charles-Dominique, T., Edelin, C., and Bouchard, A. (2010). Architectural strategies of Cornus sericea, a native but invasive shrub of Southern Quebec, Canada, under an open or a closed canopy. Annals of Botany 105, 205-220. https://doi.org/10.1093/aob/mcp273.

Charles-Dominique, T., Edelin, C., Bouchard, A., Legendre, P., and Brisson, J. (2015). Using intra-individual variation in shrub architecture to explain population cover. Oikos 124, 707-716. https://doi.org/10.1111/oik.01654

Charles-Dominique, T., Edelin, C., Brisson, J., and Bouchard, A. (2012). Architectural strategies of Rhamnus cathartica (Rhamnaceae) in relation to canopy openness. Botany 90, 976-989. https://doi. org/10.1139/b2012-069.

Costes, E., Crespel, L., Denoyes, B., Morel, P., Demene, M.-N., Lauri, P.E., and Wenden, B. (2014). Bud structure, position and fate generate various branching patterns along shoots of closely related Rosaceae species: a review. Frontiers in Plant Sci. 5. https://doi.org/10.3389/ fpls.2014.00666.

Costes, E., Sinoquet, H., Kelner, J.-J., and Godin, C. (2003). Exploring within-tree architectural development of two apple tree cultivars over 6 years. Annals of Botany 91, 91-104. https://doi.org/10.1093/ $\mathrm{aob} / \mathrm{mcg} 010$.

Cremers, G., and Edelin, C. (1995). Etude de l'architecture aérienne de quelques plantes tropicales à ramification basitone: vers une révision du modèle de Tomlinson. Canadian J. Botany 73, 14901503. https://doi.org/10.1139/b95-161

Crespel, L., Le Bras, C., Relion, D., and Morel, P. (2014). Genotype $x$ year interaction and broad-sense heritability of architectural characteristics in rose bush. Plant Breeding 133, 412-418. https:// doi.org/10.1111/pbr.12157.

Crespel, L., Sigogne, M., Donès, N., Relion, D., and Morel, P. (2013). Identification of relevant morphological, topological and geometrical variables to characterize the architecture of rose bushes in relation to plant shape. Euphytica 191, 129-140. https://doi.org/10.1007/ s10681-013-0902-6.

Creusen, M.E.H., and Schoormans, J.P.L. (2005). The different roles of product appearance in consumer choice. J. Product Innov. Manag. 22, 63-81. https://doi.org/10.1111/j.0737-6782.2005.00103.x.

Davies, D.L., and Bouldin, D.W. (1979). A cluster separation measure. IEEE transactions on Pattern Analysis and Machine Intelligence 2, 224-227. https://doi.org/10.1109/TPAMI.1979.4766909.

Demotes-Mainard, S., Bertheloot, J., Boumaza, R., Huché-Thélier, L., Guéritaine, G, Guérin, V, and Andrieu, B. (2013a). Rose bush leaf and internode expansion dynamics: analysis and development of a model capturing interplant variability. Frontiers in Plant Sci. 4. https://doi. org/10.3389/fpls.2013.00418

Demotes-Mainard, S., Huché-Thélier, L., Morel, P., Boumaza, R, Guérin, V., and Sakr, S. (2013b). Temporary water restriction or light intensity limitation promotes branching in rose bush. Sci. Hortic 150, 432-440. https://doi.org/10.1016/j.scienta.2012.12.005.

Dijksterhuis, G. (1995). Assessing panel consonance. Food Quality and Preference 6(1), 7-14. https://doi.org/10.1016/0950-3293(94) P4207-M.

Donès, N., Adam, B., and Sinoquet, H. (2006). PiafDigit-software to drive a Polhemus Fastrak 3 SPACE 3D digitiser and for the acquisition of plant architecture (Clermont-Ferrand, France: UMR PIAF INRA-UBP).

Durand, J.B., Guédon, Y., Caraglio, Y., and Costes, E. (2005). Analysis of the plant architecture via tree-structured statistical models: the hidden Markov tree models. New Phytologist 166, 813-825. https:// doi.org/10.1111/j.1469-8137.2005.01405.x.

Fay, N. (2002). Environmental arboriculture, tree ecology and veteran tree management. Arboricult. J. 26, 213-238. https://doi.or $\mathrm{g} / 10.1080 / 03071375.2002 .9747336$

Ferrante, A., Trivellini, A., Scuderi, D., Romano, D., and Vernieri, P. (2015). Post-production physiology and handling of ornamental potted plants. Postharv. Biol. and Technol. 100, 99-108. https://doi. org/10.1016/j.postharvbio.2014.09.005.

Ferraro, P., and Godin, C. (2000). A distance measure between plant architectures. Annals of Forest Sci. 57, 445-461. https://doi. org/10.1051/forest:2000134.

Ferraro, P., and Godin, C. (2003). An edit distance between quotiented trees. Algorithmica 36, 1-39. https://doi.org/10.1007/s00453-0021002-5.

Findlay, C.J., Castura, J.C., and Lesschaeve, I. (2007). Feedback calibration: A training method for descriptive panels. Food Qual. and Pref. 18, 321-328. https://doi.org/10.1016/j.foodqual.2006.02.007.

Fox, J., Weisberg, S., Adler, D., Bates, D., Baud-Bovy, G., Ellison, S., and Graves, S. (2016). car: Companion to Applied Regression (Version 2.1-2). http://cran.r-project.org/package=car.

Galopin, G., Mauget, J.-C., and Morel, P. (2010). Morphogenetic analysis of the phenotypic variability of the architectural unit of Hydrangea macrophylla. Annals of Forest Sci. 67, 309-320. https:// doi.org/10.1051/forest/2009115.

Garbez, M., Chéné, Y., Belin, É., Sigogne, M., Labatte, J.M., Hunault, G., and Galopin, G. (2016). Predicting sensorial attribute scores of ornamental plants assessed in 3D through rotation on video by image analysis: a study on the morphology of virtual rose bushes. Comp. and Electr. in Agricult. 121, 331-346. https://doi.org/10.1016/j. compag.2016.01.001

Garbez, M., Galopin, G., Sigogne, M., Favre, P., Demotes-Mainard, S., and Symoneaux, R. (2015). Assessing the visual aspect of rotating virtual rose bushes by a labeled sorting task. Food Qual. and Pref. 40, 287-295. https://doi.org/10.1016/j.foodqual.2014.06.008.

Godin, C., and Caraglio, Y. (1998). A multiscale model of plant topological structures. J. Theor. Biol. 191, 1-46. https://doi. org/10.1006/jtbi.1997.0561.

Guzmán, Q.J.A., and Cordero, R.A. (2016). Neighbourhood structure and light availability influence the variations in plant design of shrubs in two cloud forests of different successional status. Annals of Botany 118, 23-34. https://doi.org/10.1093/aob/mcw078.

Hallé, F., Oldeman, R.A.A., and Tomlinson, P.B. (1978). Tropical Trees and Forests: an Architectural Analysis (Berlin: Springer-Verlag) https://doi.org/10.1007/978-3-642-81190-6. 
Hennig, C. (2008). Dissolution point and isolation robustness: robustness criteria for general cluster analysis methods. J. Multivar Anal. 99, 1154-1176. https://doi.org/10.1016/j.jmva.2007.07.002.

Hennig, C. (2015). fpc: Flexible Procedures for Clustering (Version 2.1-10). Retrieved from https://cran.r-project.org/package=fpc.

Higginbotham, J.S. (1987). Want to sell to supermarkets? Think like a supermarket buyer. Amer. Nurseryman 165, 133-139.

Huché-Thélier, L., Boumaza, R., Demotes-Mainard, S., Canet, A., Symoneaux, R., Douillet, O., and Guérin, V. (2011). Nitrogen deficiency increases basal branching and modifies visual quality of the rose bushes. Sci. Hortic. 130, 325-334. https://doi.org/10.1016/j. scienta.2011.07.007.

Husson, F., Josse, J., Lê, S., and Mazet, J. (2016). FactoMineR: Multivariate exploratory data analysis and data mining with $\mathrm{R}$ (Version 1.31.5). http://cran.r-project.org/package=FactoMineR.

Ishii, H.T., Ford, E.D., and Kennedy, M.C. (2007). Physiological and ecological implications of adaptive reiteration as a mechanism for crown maintenance and longevity. Tree Physiol. 27, 455-462. https://doi.org/10.1093/treephys/27.3.455.

Kawamura, K., and Takeda, H. (2002). Light environment and crown architecture of two temperate Vaccinium species: inherent growth rules versus degree of plasticity in light response. Canadian J. Bot. 80, 1063-1077. https://doi.org/10.1139/b02-096.

Kawamura, K., and Takeda, H. (2004). Rules of crown development in the clonal shrub Vaccinium hirtum in a low-light understory: a quantitative analysis of architecture. Canadian J. Bot. 82, 329-339. https://doi.org/10.1139/b04-001.

Kawamura, K., Hibrand-Saint Oyant, L., Thouroude, T., Jeauffre, J., and Foucher, F. (2015). Inheritance of garden rose architecture and its association with flowering behaviour. Tree Genetics \& Genomes 11, 1-12. https://doi.org/10.1007/s11295-015-0844-3.

Kohsel, L., and Bennedsen, B.S. (2001). Performance of human experts grading pot roses in a commercial environment. Acta Hortic. 562, 273-283. https://doi.org/10.17660/ActaHortic.2001.562.32.

Kuhn, M. (2016). CARET: Classification and Regression Training (Version 6.0-68). http://cran.r-project.org/package=caret.

Kuhn, M., and Johnson, K. (2013). Applied Predictive Modeling (New York, USA: Springer). https://doi.org/10.1007/978-1-4614-6849-3.

Kuznetsova, A., Christensen, R.H.B., Bavay, C., and Brockhoff, P.B. (2015). Automated mixed ANOVA modeling of sensory and consumer data. Food Qual. and Pref. 40, 31-38. https://doi.org/10.1016/j. foodqual.2014.08.004.

Labbe, D., Rytz, A., and Hugi, A. (2004). Training is a critical step to obtain reliable product profiles in a real food industry context. Food Qual. and Pref. 15, 341-348. https://doi.org/10.1016/S09503293(03)00081-8.

Langsrud, $\varnothing$. (2003). ANOVA for unbalanced data: Use Type II instead of Type III sums of squares. Stat. and Comp. 13, 163-167. https:// doi.org/10.1023/A:1023260610025.

Le Bris, M., Champeroux, A., Bearez, P., and Le Page-Degivry, M.T. (1998). Basipetal gradient of axillary bud inhibition along a rose (Rosa hybrida L.) stem: growth potential of primary buds and their two most basal secondary buds as affected by position and age. Annals of Botany 81, 301-309. https://doi.org/10.1006/ anbo.1997.0558.

Leduc, N., Roman, H., Barbier, F., Péron, T.LH.-T., Lothier, J., and Sakr, S. (2014). Light signaling in bud outgrowth and branching in plants. Plants 3, 223-250. https://doi.org/10.3390/plants3020223.

Lenth, R.V. (2016). LSMEANS: Least-Squares Means (Version 2.23). https://cran.r-project.org/package=lsmeans.
Li-Marchetti, C., Le Bras, C., Relion, D., Citerne, S., Huché-Thélier, L., Sakr, S., and Crespel, L. (2015). Genotypic differences in architectural and physiological responses to water restriction in rose bush. Frontiers in Plant Sci. 6. https://doi.org/10.3389/fpls.2015.00355.

Meilgaard, M.C., Carr, B.T., and Civille, G.V. (2006). Sensory evaluation techniques, $4^{\text {th }}$ ed. (Boca Raton: CRC Press). https://doi. org/10.1201/b16452.

Morel, P., Galopin, G., and Donès, N. (2009). Using architectural analysis to compare the shape of two hybrid tea rose genotypes. Sci. Hortic. 120, 391-398. https://doi.org/10.1016/j.scienta.2008.11.039.

Morel, P., Crespel, L., Galopin, G., and Moulia, B. (2012). Effect of mechanical stimulation on the growth and branching of garden rose. Sci. Hortic. 135, 59-64. https://doi.org/10.1016/j. scienta.2011.12.007.

Murray, A.T., and Shyy, T.-K. (2000). Integrating attribute and space characteristics in choropleth display and spatial data mining. Int. J. Geograph. Inform. Sci. 14, 649-667. https://doi. org/10.1080/136588100424954.

Næs, T., Brockhoff, P., and Tomic, O. (2011). Statistics for Sensory and Consumer Science (Chichester: John Wiley \& Sons).

Nakagawa, S., and Schielzeth, H. (2013). A general and simple method for obtaining $\mathrm{R}^{2}$ from generalized linear mixed-effects models. Meth. in Ecol. and Evol. 4, 133-142. https://doi.org/10.1111/j.2041210x.2012.00261.x.

Pallas, B., Da Silva, D., Valsesia, P., Yang, W., Guillaume, O., Lauri, P.E., and Costes, E. (2016). Simulation of carbon allocation and organ growth variability in apple tree by connecting architectural and source-sink models. Annals of Botany 118, 317-330. https://doi. org/10.1093/aob/mcw085.

Pateiro-López, B., and Rodrıguez-Casal, A. (2010). Generalizing the convex hull of a sample: the R package alphahull. J. Statist. Softw. 34, 1-28. https://doi.org/10.18637/jss.v034.i05.

Pearcy, R.W., Muraoka, H., and Valladares, F. (2005). Crown architecture in sun and shade environments: assessing function and trade-offs with a three-dimensional simulation model. New Phytol. 166, 791-800. https://doi.org/10.1111/j.1469-8137.2005.01328.x.

Pradal, C., Dufour-Kowalski, S., Boudon, F., Fournier, C., and Godin, C. (2008). OpenAlea: a visual programming and component-based software platform for plant modelling. Funct. Plant Biol. 35, 751760. https://doi.org/10.1071/FP08084.

R Development Core Team. (2015). R: A language and environment for statistical computing (Version 3.2.3). (Vienna, Austria: R Foundation for Statistical Computing). http://www.R-project.org/.

Raimbault, P., and Tanguy, M. (1993). La gestion des arbres d'ornement. $1^{\text {re }}$ partie : une méthode d'analyse et de diagnostic de la partie aérienne. Revue Forestière Française XLV, 97-117. https:// doi.org/10.4267/2042/26414

Rainey, B.A. (1986). Importance of reference standards in training panelists. J. Sensory Studies 1, 149-154. https://doi.org/10.1111/ j.1745-459X.1986.tb00167.x.

Rossi, F. (2001). Assessing sensory panelist performance using repeatability and reproducibility measures. Food Qual. and Pref. 12, 467-479. https://doi.org/10.1016/S0950-3293(01)00038-6.

Santagostini, P., Demotes-Mainard, S., Huché-Thélier, L., Leduc, N., Bertheloot, J., Guérin, V., and Boumaza, R. (2014). Assessment of the visual quality of ornamental plants: Comparison of three methodologies in the case of the rosebush. Sci. Hortic. 168, 17-26. https://doi.org/10.1016/j.scienta.2014.01.011.

Schreiner, M., Korn, M., Stenger, M., Holzgreve, L., and Altmann, M. (2013). Current understanding and use of quality characteristics of horticulture products. Sci. Hortic. 163, 63-69. https://doi. org/10.1016/j.scienta.2013.09.027. 
Scuderi, D., Giuffrida, F., Toscano, S., and Romano, D. (2012). Growth, physiological response, and quality characteristics of weeping fig in response to shading levels and climatic conditions. HortScience 47, 1586-1592

Segura, V., Ouangraoua, A., Ferraro, P., and Costes, E. (2008). Comparison of tree architecture using tree edit distances: application to 2-year-old apple hybrids. Euphytica 161, 155-164. https://doi. org/10.1007/s10681-007-9430-6.

Silva, L., Koga, M.L., Cugnasca, C.E., and Costa, A.H.R. (2013). Comparative assessment of feature selection and classification techniques for visual inspection of pot plant seedlings. Comp. and Electron. in Agricult. 97, 47-55. https://doi.org/10.1016/j. compag.2013.07.001.

Spilke, J., Piepho, H.-P., and Hu, X. (2005). A simulation study on tests of hypotheses and confidence intervals for fixed effects in mixed models for blocked experiments with missing data. J. Agricult., Biol., and Environm. Statistics 10(3), 374-389. https://doi. org/10.1198/108571105X58199.

Steinley, D. (2006). K-means clustering: a half-century synthesis. British J. Math. and Statist. Psychol. 59, 1-34. https://doi. org/10.1348/000711005X48266.

Sterck, F.J., Duursma, R.A., Pearcy, R.W., Valladares, F., Cieslak, M., and Weemstra, M. (2013). Plasticity influencing the light compensation point offsets the specialization for light niches across shrub species in a tropical forest understorey. J. Ecology 101, 971-980. https://doi. org/10.1111/1365-2745.12076.

Stone, H., Sidel, J., and Singleton, R.C. (1974). Sensory evaluation by quantitative descriptive analysis. Food Technol. 28, 24-34.

Townsley-Brascamp, W., and Marr, N.E. (1994). Evaluation and analysis of consumer preferences for outdoor ornamental plants. Acta Hortic. 391, 199-208.

Valladares, F., Wright, S.J., Lasso, E., Kitajima, K., and Pearcy, R.W. (2000). Plastic phenotypic response to light of 16 congeneric shrubs from a Panamanian rainforest. Ecology 81, 1925-1936. https://doi. org/10.1890/0012-9658(2000)081[1925:PPRTLO]2.0.CO;2.

Walesiak, M., and Dudek, A. (2015). clusterSim: Searching for Optimal Clustering Procedure for a Data Set (Version 0.44-2). https://cran.rproject.org $/$ package $=$ clusterSim.

Wolters, C.J., and Allchurch, E.M. (1994). Effect of training procedure on the performance of descriptive panels. Food Qual. and Pref. 5, 203-214. https://doi.org/10.1016/0950-3293(94)90036-1.

Yeo, I.K., and Johnson, R.A. (2000). A new family of power transformations to improve normality or symmetry. Biometrika 87 , 954-959. https://doi.org/10.1093/biomet/87.4.954.

Zieslin, N., and Mor, Y. (1981). Plant management of greenhouse roses. Formation of renewal canes. Sci. Hortic. 15, 67-75. https:// doi.org/10.1016/0304-4238(81)90063-7.

Zieslin, N., and Mor, Y. (1990). Light on roses. A review. Sci. Hortic. 43, 1-14. https://doi.org/10.1016/0304-4238(90)90031-9.

Zucchini, W. (2000). An introduction to model selection. J. Math. Psychol. 44, 41-61. https://doi.org/10.1006/jmps.1999.1276.
Received: May 5, 2017

Accepted: Feb. 20, 2018

Addresses of authors:

M. Garbez ${ }^{1,2}$, R. Symoneaux ${ }^{3}$, É. Belin ${ }^{4}$, Y. Caraglio ${ }^{5}$, Y. Chéné ${ }^{4}$,

N. Donès ${ }^{6}$, J.-B. Durand ${ }^{7,8}$, G. Hunault ${ }^{9}$, D. Relion ${ }^{1}$, M. Sigogne $^{1}$,

D. Rousseau ${ }^{10}$ and G. Galopin ${ }^{1, *}$

${ }^{1}$ IRHS, INRA, Agrocampus Ouest, Université d'Angers, SFR

4207 QUASAV, 42 rue Georges Morel, CS 60057,

49071 Beaucouzé Cedex, France

2 Pépinières Desmartis, route d'Agen, 24100 Bergerac,

France

${ }^{3}$ Unité de Recherche GRAPPE, Université Bretagne Loire,

Ecole Supérieure d'Agricultures (ESA), INRA, SFR 4207

QUASAV, 49000 Angers Cedex, France

${ }^{4}$ Université d'Angers, Laboratoire Angevin de Recherche en Ingénierie des Systèmes (LARIS) EA 731, 62 avenue Notre

Dame du Lac, 49000 Angers, France

${ }^{5}$ AMAP, CIRAD, CNRS, INRA, IRD, UM, 34398 Montpellier Cedex 5, France

${ }^{6}$ PIAF, INRA, UCA, 63000 Clermont-Ferrand, France

${ }^{7}$ Virtual Plants, C.C. 06002 95, rue de la Galéra,

34095 Montpellier Cedex 5, France

${ }^{8}$ Laboratoire Jean Kuntzmann, MISTIS, INRIA Grenoble, Rhône-Alpes, 655 avenue de l'Europe, Montbonnot 38334 Saint Ismier Cedex, France

${ }^{9}$ Université d'Angers, Laboratoire Hémodynamique, Interaction, Fibrose, et Invasivité Tumorale Hépatique (HIFIH) UPRES EA 3859, SFR 4208 ICAT, 4 rue Larrey, 49933 CHU Angers, France

${ }^{10}$ Université de Lyon, Centre de Recherche en Acquisition et Traitement de l'Image pour la Santé (CREATIS), CNRS UMR 5220, INSERM - U1044, Université Lyon 1, INSALyon, 20 avenue Albert Einstein, 69621 Villeurbanne, France

* Corresponding author;

E-mail: gilles.galopin@agrocampus-ouest.fr Postal address: Agrocampus Ouest, 2 rue Le Nôtre, 49045 Angers Cedex 01, France Tel.: (+33)-241-225-430 